Bidik

Vol. 1 No. 1 Oktober 2020

$38-42$

\title{
Peningkatan Kemampuan Poetry Reading Komunitas Belajar HMJ Sastra Indonesia dan Sastra Inggris Universitas Lancang Kuning
}

\author{
Edward*, Sorta Hutahaean, Junaidi \\ Fakultas Ilmu Budaya, Universitas Lancang Kuning \\ Email : edward@unilak.ac.id
}

\begin{abstract}
The title of this community service is "Increasing the Poetry Reading Ability of the Learning Community of HMJ Indonesian Literature and English Literature, Faculty of Cultural Sciences, Lancang Kuning University. The aim of this training is to provide knowledge and skills about reading English poetry to the Indonesian and English Literature HMJ community. The ability to read English poetry is both receptive and productive. Receptive because they have to understand the meaning referred to in the poetry text, and productive when doing or giving appreciation. To improve students' reading skills, it is necessary to provide training on English poetry reading techniques properly and correctly so that students gain experience and knowledge that can be used in appreciation.
\end{abstract}

Key words: Poetry, Reading

\begin{abstract}
Abstrak
Judul pengabdian kepada masyarakat ini adalah "Peningkatan Kemampuan Poetry Reading Komunitas Belajar HMJ Sastra Indonesia dan Sastra Inggris Fakultas Ilmu Budaya Universitas Lancang Kuning. Tujuan pelatihan ini ialah untuk memberikan pengetahuan dan keterampilan tentang membaca puisi Inggris kepada komunitas HMJ Sastra Indonesia dan Sastra Ingris. Kemampuan membaca puisi bahasa inggris bersifat reseptif sekaligus produktif. Reseptif karena harus memahami makna yang dimaksud di dalam teks puisinya, dan produktif ketika melakukan atau memberikan apresisinya. Untuk meningkatkan kemampuan membaca mahasiswa, perlu diberikan pelatihan tentang teknik membaca puisi Inggris dengan baik dan benar sehingga mahasiswa mendapatkan pengalaman dan pengetahuan yang dapat digunakan dalam berapresiasi.
\end{abstract}

Kata kunci: Poetry Reading

\section{Pendahuluan}

Sebagai salah satu karya-karya sastra, puisi termasuk yang paling unik karena singkat dan padat. Untuk menceritakan atau memaparkan sesuatu, puisi bisa dibuat hanya dalam satu stanza saja bahkan satu kalimat. Tidak seperti karya lainnya, novel, berupa cerita atau narasi yang relatif panjang. Penyampaian cerita di dalam novel dikemas dalam ploting yang tentunya terdiri atas beberapa kalimat bahkan paragraf. 
Satu cerita atau novel bisa terdiri atas puluhan bahkan ratusan halaman, sementara puisi bisa/ cukup di dalam satu halaman atau satu paragraf dalam bentuk stanza.

Poetry reading (membaca puisi) adalah suatu ilmu seni yang menuntut keterampilan tersendiri. Membaca puisi berarti menghayati makna/ pesan yang terkandung di dalam teks puisi tersebut, kemudian membacakannya untuk didengar oleh orang lain dengan pengertian bahwa ungkapan, perasaan dan maksud dari penulis/ penyair dapat direpresentasikan. Untuk mengapresiasi karya tersebut dalam bentuk audibel dan visual, tentunya seorang pembaca puisi harus memilki konsep dan teknik yang sesuai agar dapat merepresentasikan ungkapan yang dituangkan oleh penulis/ penyair dalam karya puisinya.

Poetry reading sering ditampilkan dalam acara-acara formal dan informal, seperti dalam kegiatan atau pagelaran seni. Berdasarkan latar belakang ini dapat dikatakan bahwa pembacaan puisi cukup sering dilakukan dalam berbagai kegiatan, namun puisi yang dibacakan adalah puisi karya sastra Indonesia. Mahasiswa tidak pernah tampil membawakan puisi Inggris di depan publik. Fenomena ini bisa saja disebabkan oleh ketidakmampuan atau ketidakpercayaan mahasiswa dalam membawakan poetry reading.

Berdasarkan fenomena di atas penulis/ tim merasa tertarik untuk memberikan masukan dan berbagi pengetahuan kepada mitra agar di masa mendatang mitra lebih bersiap untuk berapresiasi dalam menampilkan poetry reading.

Seperti disebutkan di atas, kegiatan poetry reading menuntut kemahiran seseorang karena puisi itu tidak bisa hanya dilafalkan begitu saja, namun harus menurut sistem pelafalan dan beberapa teknik-teknik lainnya. Dengan demikian hal ini menjadi permasalahan bagi mitra sehingga kegiatan poetry reading dalam bahasa Inggris tidak pernah dilakukan.

\section{Pedekatan Pelaksanaan Program}

Kegiatan Ibm ini dilakukan pada komunitas belajar dan english studi club mahasiswa Prodi Sastra Inggris dan Sastra Indonesia Fakultas Ilmu Budaya Universitas Lancang Kuning, berjumlah 10-12 orang. Adapaun pelaksanaan kegiatan dilakukan dalam beberapa tahap sebagai berikut:

1. Melakukan pre-test, mahasiswa diminta praktek membaca dan menentukan tekanan ucapan puisi dalam stanza.

2. Memberikan ceramah tentang definisi, konsep dan siknifikansi poetry reading. Pada tahap ini ditransfer aspek-aspek yang harus disikapi, seperti teknik berdiri atau gerakan/ mobilitas, cara menentukan tekanan dan formula irama.

Peralatan yang diperlukan adalah:

- Hands out

- Power Point

- Media

3. Tahap ini adalah tahap post-test di mana mahasiswa kembali diminta praktik. 


\section{Pelaksanaan Program}

Kegiatan berdampak sangat positif bagi mitra karena terdapat perbedaan yang sangat siknifikan antara hasil sebelum pelatihan dan sesudah pelatihan. Tim memberikan pre-test untuk mendapatakan data, dilakukan treatment dan kemudian postest. Adapun jumlah mahasiswa yang dijadualkan mengikuti pelatihan ini sekitar 10-12 orang.

Secara menyeluruh pemahaman akan signifikansi poetry reading masih sangat asing atau belum diketahui oleh mitra. Pada saat pre-test mitra sama sekali tidak tahu mengetahui cara yang benar menyampaikan informasi yang akan disampaikan melalui pembacaan karya puisi. Mitra membaca karya puisi yang disajikan dengan datar seperti layaknya membaca artikel atau wacana bacaan umum. Hal ini mengindikasikan bahwa hal pembacaan suatu puisi memang masih asing. Formula dan tekanan suatu kata tidak diketahui oleh mitra.

Setelah dilakukan treatment mitra sudah memiliki self-confidence, sudah mengetahui apa yang harus dilakukan saat pertama melihat suatu puisi dan kemudian membacakannya.

Berikut adalah contoh kuis pre test/ post test

1. Tentukan pola/ meter dalam pusi berikut.

2. Tentukan tekanan pada setiap kata dalam puisi berikut.

\section{Nothing Gold Can Stay}

Nature's first green is gold, Her hardest hue to hold. Her early leaf's a flower; But only so an hour.

Then leaf subsides to leaf, So Eden sank to grief, So dawn goes down today

Nothing gold can stay

\section{Fire and Ice}

Some say the world will end in fire, Some say ih ice.

From what I've tasted of desire I hold with those who favor fire. But if it had to perish twice, I think I know enough of hate To know that for destruction ice Is also great And would suffice. 


\section{The Road Not Taken}

Two roads diverged in a yellow wood, And sorry I could not travel both And be one traveler, long I stood And looked down one as far as I could To where it bent in the undergrowth;

Then took the other, as just as fair And having perhaps the better claim, Because it was grassy and wanted wear; Though as for that, the passing there Had worn them really about the same,

And both that morning equally lay In leaves no step had trodden black Oh, I kept the first for another day! Yet knowing how way leads on to way, I doubted if I should ever come back.

I shall be telling this with a sigh Somewhere ages and ages hence: two roads diverged in a wood, and I -I took the one less traveled by, And that has made all the difference.

Adapun luaran yang dicapai ialah memberdayakan mitra sehingga mitra mendapatkan pengetahuan tentang ilmu poetry reading serta mengevaluasi ilmu tersebut untuk dapat digunakan/ dipraktekkan sesuai kebutuhan. Selanjutnya, sesuai dengan target yang disebutkan terdahulu, luaran dari pengabdian ini juga dirancangan sebagai publikasi ilmiah atau artikel.

\section{Refleksi Capaian Program}

Berdasarkan pemaparan di atas dapat disimpulkan bahwa rangkaian kegiatan pengabdian menunjukkan pengaruh positif, yakni peningkatan kemampuan mitra sebagai pembaca karya sastra khususnya puisi di depan khalayak dalam suasana formal.

\section{Penutup}

Adapun saran yang dapat disebutkan pada saat ini adalah:

1. Strategi pelatihan yang diberikan dapat dimanfaatkan dengan sebaik-baiknya oleh mitra/ mahasiswa dalam belajar secara mandiri dan membuatnya sebagai bekal ilmu yang praktikal di masa mendatang. 
2. Penindaklanjutan dari program ini/ strategi-strategi pembelajaran yang singkat, sederhana perlu tetap diperhatikan, karena sangat membantu pada tahap proses belajar dan pembelajaran baik di kampus maupun secara mandiri. Pelatihan ini perlu dilanjutkan agar ilmu dan keterampilan mitra/ mahasiswa benar-benar siap pakai.

\section{Daftar Pustaka}

Bennet, Kat Bradley. 2007. Teaching Pronunciation: An Independent Study Course for Teachers of Adult English as Second Language Learners. Longmont, CO 80501:Northern Colorado Professional Development Centre.

Brown, H.D. 1994. Principles of Language Learning and Teaching. 3rd ed. Englewood Cliffs NJ: Prentice Hall.

Brown, H. Douglas. 2004. Language Assessment. New York: Pearson Education, Inc.

Damono Djoko Sapardi,1997. Sosiologi Sastra. Jakarta: Pusat Bahasa, Departemen Pendidikan Nasional.

Faggen, Roberts, 2009, The Cambridge Introduction to Robert Frost, New York: Cambridge University Press

Frost, Roberts, 1946, The Poem of Roberts Frost, New York: Random House,Inc

Gilakjani, P Abbas. 2012. The Significance of Pronunciation in English Language Teaching. International Journal of Language Teaching: International Journal of Language Teaching and Research Vol. 5, No.4

Hadi, 2009. Teaching Pronunciation by Using Audio Lingual: Blogspot.com

Harmer, Jeremy. 1998. How to Teach English. England: Addison Wesley Longman.

Nunan, David. 1999. Second language Teaching and Learning. Boston: Heinle \& Heinle Publishers.

Rivers, W. M. 1981. Teaching Foreign-Language Skills. Chicago: The University of Chicago Press. 